\title{
Analysis of Geomagnetically Induced Currents (GIC) at Equatorial Region over Solar Cycle 24
}

\author{
Zatul Iffah Abd Latiff and Mohamad Huzaimy Jusoh
}

\begin{abstract}
Geomagnetically induced currents (GIC) are one of the ground-end embodiments correlated with space environment perturbations owing to the Sun-Earth system's electromagnetic coupling. This natural hazard has contributed to the collapse of the global power grid, particularly during an extreme geomagnetic storm. For this study, global geomagnetic field data for equatorial regions focused on 9 extreme geomagnetic storms during solar cycle 24 were examined to explore the trend of GIC-related events centered on the temporal variations of horizontal element of geomagnetic field (dH/dt). The findings showed that there is a growing increase in the level of GIC as geomagnetic latitude (MLAT) crosses dip equator $\left( \pm 3^{\circ}\right)$ due to Equatorial Electrojet (EEJ) Intensification. In equatorial region, a large number of extreme GIC events are also found to have occurred over dayside. From the correlation study carried out between the Solar Wind (SW) parameter and the GIC activities, it can be inferred that the GIC activities at the equatorial region during solar cycle 24 indicate a strong dependency on solar wind input energy ( $\varepsilon$ Parameter) and solar wind dynamic pressure (Pdyn parameter). In contrast, the Interplanetary Magnetic Field (IMF) $\mathrm{Bz}$ component parameter exhibits the least dependency relationship.
\end{abstract}

Index Terms - Geomagnetically Induced Currents (GIC), temporal variation of horizontal element of geomagnetic field (dH/dt), equatorial region, space weather, solar cycle 24

\section{INTRODUCTION}

$\mathrm{S}_{\mathrm{c}}^{\mathrm{o}}$ OLAR activities play significant role in electromagnetic coupling of Sun-Earth system. This Sun-Earth interactions have led to various types of geomagnetic disturbances. Different types of geomagnetic storm events exhibit different variation of SW parameter thus cause different geomagnetic activities on the earth's surface. One of the related geomagnetic activities is GIC which become one of the threats to electricity supplier. With our high reliance upon reliable electricity supplies, GIC is an important challenge for society [1], [2]. GIC is emerged from the induced geoelectric fields generated by the

This manuscript is submitted on $20^{\text {th }}$ May 2021 and accepted on $27^{\text {th }}$ August 2021. Zatul Iffah Abd Latiff is with College of Engineering, Universiti Teknologi MARA Cawangan Johor, Kampus Pasir Gudang, 81750 Masai, Johor. (email : zatul 0130@uitm.edu.my)

Mohamad Huzaimy Jusoh is with College of Engineering, Universiti Teknologi MARA, 40450 Shah Alam, Selangor. (email : huzaimy@uitm.edu.my)

1985-5389/C 2021 The Authors. Published by UiTM Press. This is an open access article under the CC BY-NC-ND license (http://creativecommons.org /licenses/by-nc-nd/4.0/). fluctuations of earth's magnetic field in the near-Earth space environment through Faraday's law [3], [4]. GIC are well known to occur during severe geomagnetic storms, most notably those caused by coronal mass ejections (CME) event from the Sun. Particularly, in detail, this natural threat phenomena arises from high variation of geomagnetic field due to high intensification of the ionospheric current. Sudden changes of geomagnetic field have caused induced geoelectric field that was responsible in driving GIC into the power electrical system [4]. As described previously, this phenomenon can be theoretically explained by the Faraday Law of Induction where the induced geoelectric field can be deduced from the temporal change of magnetic field as presented in (1).

$$
\nabla \times E=-\frac{\partial B}{\partial t}
$$

This ground signature of solar activities can potentially cause adverse effects to technological system at the atmosphere, earth surface and buried technological equipement such as radio communication, pipelines, railway, power network and oil and gas related technologies [5], [6].

Earlier research foused on quantifying and modeling the effects of GIC in the area of high latitude region as GIC is deemed the most severe in auroral areas, beneath the auroral electrojets [7]. Some recent investigations have indicated that the equatorial border of the high GIC threat region ranges from $50 \circ$ and $60 \circ$ magnetic latitude [8]-[10]. A lot of attentions are focused on high latitude region as this region is more vulnerable to GIC risk during the severe geomagnetic storm. During extreme geomagnetic disturbances, the latitudinal study showed that high latitude region showed comparatively high GIC levels, as opposed to low latitude and mid latitude region [11]. However, the susceptibility of GIC in equatorial and low latitude region is high during the geomagnetic storm onset on the entry of interplanetary shock wave.

According to an earlier study focused on the impact of GIC in equatorial region, this study revealed on the reported power failure occurred in this region [12]. However the focus of this research was geomagnetic storms that took place during solar cycle 23. In addition, the quantification of the relationship between SW Parameter and GIC activities were not presented 
in this study. A prior research, which utilised the $\mathrm{dH} / \mathrm{dt}$ analysis to examine the GIC activities has used the Dst index as its geomagnetic indices [13]. When comparing Dst index to SYM$\mathrm{H}$ index, it's clear that the Dst index has lower resolutions, and hence will not be able to capture the detail variations in geomagnetic activity in response to space weather disturbances. Also, it will not be adequate to extrapolate the GIC activity trends based on the two geomagnetic storms occurrences that occurred in solar cycle 24. Therefore in this research, GIC activities in the equatorial are analysed using $\mathrm{dH} / \mathrm{dt}$ analysis in the course of 9 severe geomagnetic storms over solar cycle 24 . The research includes GIC level analysis according to Geomagnetic Latitude (MLAT), number of GIC activities on the basis of Local Time (LT) and the association between GIC levels and SW Parameter in the Equatorial region.

\section{METHODOLOGY AND DATA ANALYSIS}

As mentioned in the preceding section, objectives outlined in this analysis are intended to look into the pattern of GIC activities and the interrelationship between GIC level and SW parameter in equatorial region during solar cycle 24 . In order to achieve these outlined objectives, parameters required for the study are SW parameter and $\mathrm{dH} / \mathrm{dt}$ analysis as an indicator for GIC activities. The focus of the study was on the severe geomagnetic storms that took place in the course of solar cycle 24. The geomagnetic storms selection is dependent on the minimum SYM-H index value which is must be at least equal or less than $-100 \mathrm{nT}$. Table I presents the list of chosen geomagnetic storms while the entire analysis is condensed in Fig. 1.

TABLE I

THE LIST OF 9 SELECTED SEVERE GEOMAGNETIC STORMS DURING SOLAR CYCLE 24

\begin{tabular}{lllc}
\hline \hline No & \multicolumn{1}{c}{ Event } & Storm Onset & $\begin{array}{c}\text { Minimum } \\
\text { SYM-H index } \\
(\mathrm{nT})\end{array}$ \\
\hline 1 & $26^{\text {th }}$ September 2011 & $1750 \mathrm{UT}$ & -116 \\
\hline 2 & $24^{\text {th }}$ October 2011 & $1831 \mathrm{UT}$ & -135 \\
\hline 3 & $14^{\text {th }}$ July 2012 & $1810 \mathrm{UT}$ & -123 \\
\hline 4 & $17^{\text {th }}$ March 2013 & $0600 \mathrm{UT}$ & -132 \\
\hline 5 & $31^{\text {st }}$ May 2013 & $1617 \mathrm{UT}$ & -137 \\
\hline 6 & $17^{\text {th }}$ March 2015 & $0445 \mathrm{UT}$ & -234 \\
\hline 7 & $22^{\text {nd }}$ June 2015 & $1833 \mathrm{UT}$ & -208 \\
\hline 8 & $19^{\text {th }}$ December 2015 & $1617 \mathrm{UT}$ & -170 \\
\hline 9 & $7^{\text {th }}$ September 2017 & $2350 \mathrm{UT}$ & -146 \\
\hline \hline
\end{tabular}

\section{A. The Temporal Variation of Horizontal Element of Geomagnetic Field}

The geomagnetic field reading is obtained from the flux magnetometer installed on the ground. There are several groups

of network observatories working on compilation of global geomagnetic field such as MAGDAS network, INTERMAGNET network and SUPERMAG network. The geomagnetic field data from the SUPERMAG global network were collected for this research study. SuperMAG is a global partnership between organizations and national agencies which

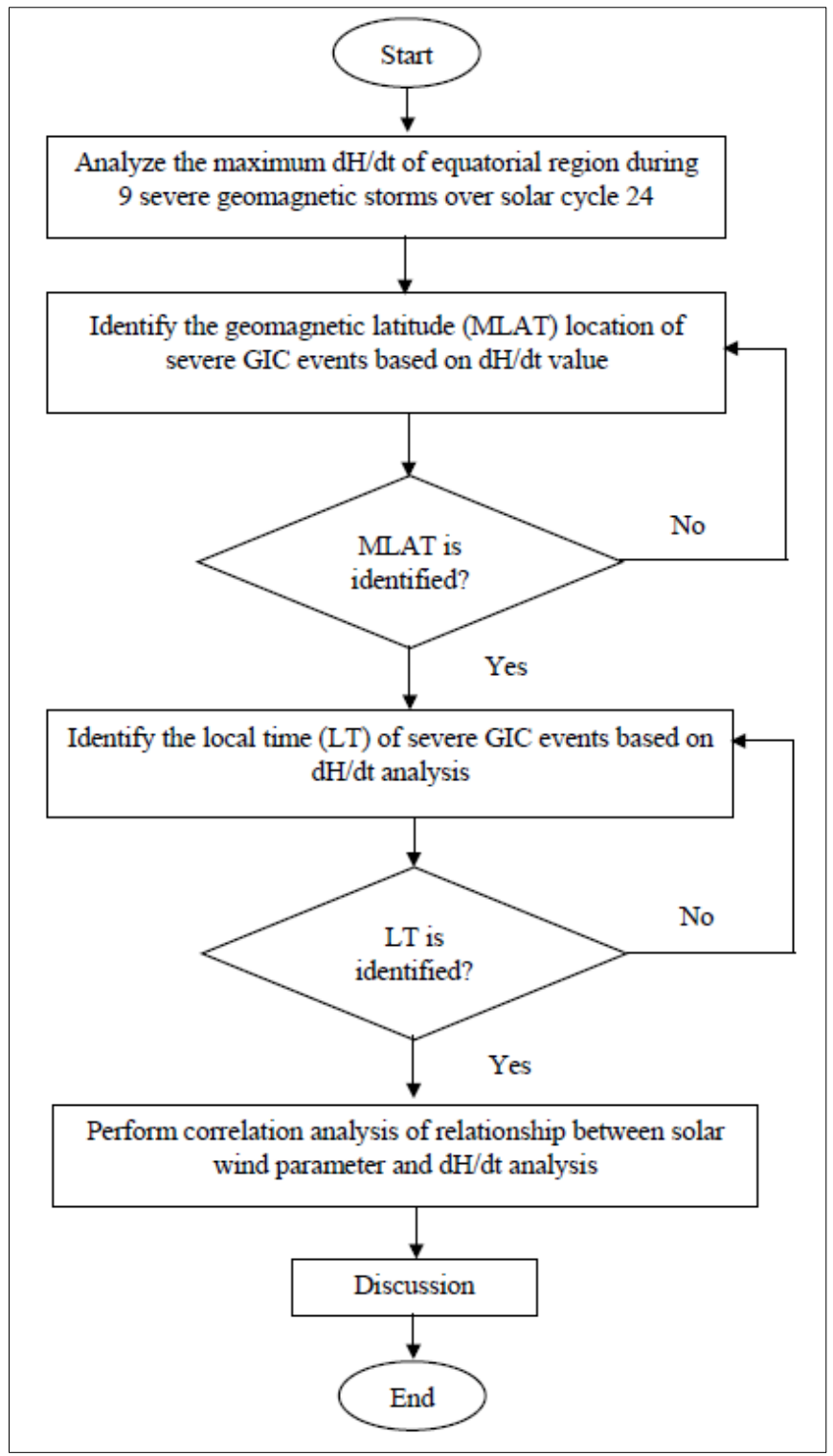

Fig. 1 The overall flowchart of the study

operates over 300 terrestrial magnetometers at the present time. In the same coordinate scheme and in the same time resolution, SuperMAG offers convenient access to validated ground magnetic field perturbations. Table II represents the list of stations involved in this analysis. Since the scope of the analysis in this study is limited to Equatorial region, the range of latitude of selected Magnetometer stations is restricted to $-15^{\circ}$ to $15^{\circ}$. The geomagnetic field data constitutes of three elements which are Horizontal Element (H), Declination Element (D) and Vertical Element (Z). For GIC study, reading is focused on the Horizontal Element. The $\mathrm{dH} / \mathrm{dt}$ is originated from the time derivative of Horizontal Element of geomagnetic field where the changes of geomagnetic field is calculated in every 1 minute to observe any abrupt increase in the geomagnetic field reading at regions of interest. Therefore $\mathrm{dH} / \mathrm{dt}$ analysis is utilized to denote any GIC activities at selected region [14]. In this analysis, selection of the stations are made by considering the stations that experienced at least minimum requirement value of maximum $\mathrm{dH} / \mathrm{dt}$ as previously highlighted in the study 
conducted by [15][11]. As stated by these studies, the presence of GIC activities can be determined by the minimum requirement of the $\mathrm{dH} / \mathrm{dt}$ value $\geq 30 \mathrm{nT} / \mathrm{min}$.

TABLE II

LIST OF GROUND-BASED MAGNETOMETERS IN EQUATORIAL REGION BASED ON ITS GEOMAGNETIC LATITUDE (MLAT)

\begin{tabular}{ccccc}
\hline \hline No & Code & Name & Country & MLAT $\left(^{\circ}\right)$ \\
\hline $\mathbf{1}$ & AAE & Addis Ababa & Ethiopia & -0.06 \\
\hline $\mathbf{2}$ & JRS & Alem Ecua & Ecuador & 12.1 \\
\hline $\mathbf{3}$ & ABG & Alibag & India & 11.99 \\
\hline $\mathbf{4}$ & ANC & Ancon & Panama & 1.44 \\
\hline $\mathbf{5}$ & BCL & Bac Lieu & Vietnam & 1.41 \\
\hline $\mathbf{6}$ & CDO & Cagayan De oro & Phillippines & 0.61 \\
\hline $\mathbf{7}$ & A03 & Cameroon & Cameroon & -11.1 \\
\hline $\mathbf{8}$ & CEB & Cebu & Phillippines & 2.66 \\
\hline $\mathbf{9}$ & BCL & Dalat & Vietnam & 4.3 \\
\hline $\mathbf{1 0}$ & A08 & Davao & Phillippines & -0.85 \\
\hline $\mathbf{1 1}$ & EUS & Eusebio & Brazil & -6.82 \\
\hline $\mathbf{1 2}$ & GAN & Gan & Maldives & -7.77 \\
\hline $\mathbf{1 3}$ & GUA & Guam & United States & 5.64 \\
\hline $\mathbf{1 4}$ & HUA & Huancayo & United States & 1.17 \\
\hline $\mathbf{1 5}$ & HYB & Hyderabad & India & 10.36 \\
\hline $\mathbf{1 6}$ & ICA & Ica & Ica & -0.68 \\
\hline $\mathbf{1 7}$ & KOU & Kourou & France & 8.62 \\
\hline $\mathbf{1 8}$ & LKW & Langkawi & Malaysia & -2 \\
\hline $\mathbf{1 9}$ & LGZ & Legazpi & Phillippines & 5.52 \\
\hline $\mathbf{2 0}$ & MBO & Mbour & Senegal & 1.2 \\
\hline $\mathbf{2 1}$ & MUT & Muntinlupa & Vietnam & 6.9 \\
\hline $\mathbf{2 2}$ & NAB & Nairobi & Kenya & -11.15 \\
\hline $\mathbf{2 3}$ & TAM & Tamanrasset & Algeria & 8.92 \\
\hline $\mathbf{2 4}$ & TIR & Tirunelveli & India & 0.57 \\
\hline $\mathbf{2 5}$ & VRE & Villa Remedios & Bolivia & -4.53 \\
\hline $\mathbf{2 6}$ & YAP & Yap & Federated & 1.24 \\
& & States of & \\
\hline \hline & & Micronesia & \\
\hline & & & \\
\hline
\end{tabular}

\section{B. Solar Wind Parameter}

Depending on the severity levels of the geomagnetic storms as distinguished by the SYM-H index, some selections of geomagnetic storms during solar cycle 24 were considered. The global magnetic field heterogeneity is constituted by the SYM$\mathrm{H}$ index. In order to minimize the influence of auroral electrojet and equatorial electrojet, SYM-H index is obtained based on geomagnetic field extracted from ground-based magnetometers located at low and mid latitude region. The geomagnetic storm events selected in this study are confined in Table III based on the categorization of geomagnetic activites [16].

TABLE III

CLASSIFICATION OF GEOMAGNETIC STORM BASED ON SYM-H INDEX

\begin{tabular}{ccc}
\hline \hline No. & Geomagnetic Storm & SYM-H index \\
\hline 1 & Super & $-100>$ SYM-H $\geq-250$ \\
\hline 2 & Intense & $-50>$ SYM-H $\geq-100$ \\
\hline 3 & Moderate & $-30>$ SYM-H $\geq-50$ \\
\hline 4 & Small & SYM-H $\geq-50$ \\
\hline \hline
\end{tabular}

\section{RESULTS AND DISCUSSION}

The study of the GIC level intensity in the equatorial region requires an assessment of $\mathrm{dH} / \mathrm{dt}$ based on various geomagnetic storm events. Fig. 2 shows Geomagnetic activity summary from 22nd June -24th June 2015 while Fig. 3 illustrates the variation of $\mathrm{dH} / \mathrm{dt}$ analysis of several representative locations in the equatorial region during a severe geomagnetic storm event on 22nd June - 24th June 2015. The severe geomagnetic storm on 22 nd June - 24th June began at approximately at 1830 UT when an interplanetary shock wave from coronal mass ejection passed the Earth as presented in Fig. 2. An abrupt increasing pattern of solar wind speed (Vsw), from 436 to $639 \mathrm{~km} / \mathrm{s}$ before a next increase until over $700 \mathrm{~km} / \mathrm{s}$ was observed as shown in the top panel. This CME impact caused strong compression during the SSC onset with the value of Pdyn paramater was almost reached to $60 \mathrm{nPa}$. The IMF Bz Component oriented to positive direction during the first shock before it has oscillated to negative and positive directions which corresponded to the series of Vsw abrupt increases from 22nd June until 23rd June 2015. High ground magnetic perturbations were clearly observed through SYMH-index where it decreases until -208 nT simultaneously with the high inject of $\varepsilon$ Parameter of almost $1.27 \times 1020(\mathrm{erg} / \mathrm{min})$ before the SYM-H index gradually increase to the initial state at the next day.

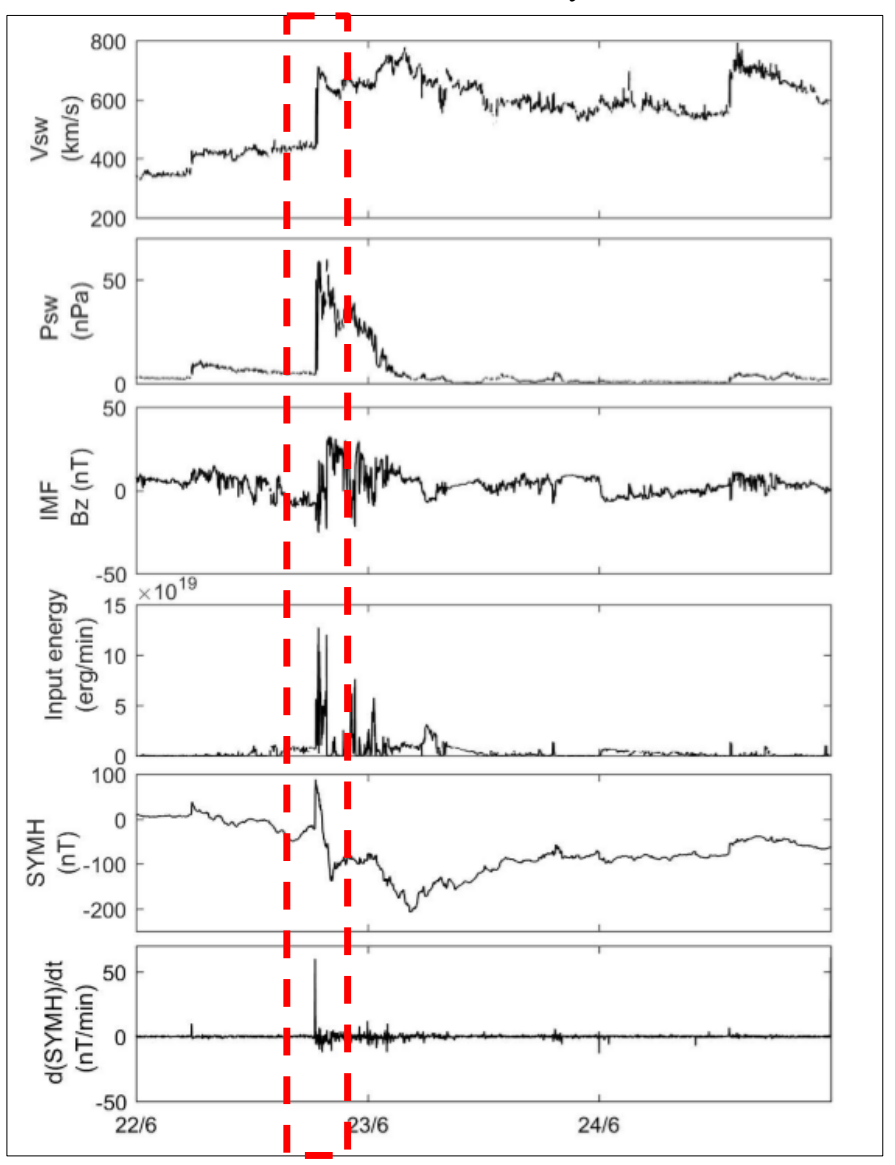

Fig. 2 An illustration of $\mathrm{dH} / \mathrm{dt}$ analysis for Equatorial Region during the 22nd24th June 2015 Severe Geomagnetic Storm 
Based on Fig. 3, it shows that the maximum $\mathrm{dH} / \mathrm{dt}$ occurred at the moment where the interplanetary shock arrived approximately around 1830 UT. Most of the equatorial stations indicate maximum $\mathrm{dH} / \mathrm{dt}$ during same time, however there is a delay after the onset of geomagnetic storms experienced by some equatorial stations. Therefore, in order to perform a detail investigation of GIC level during 9 severe geomagnetic storms over Solar Cycle 24, several analysis are performed ; 1) The assesment on the averaged value of $\mathrm{dH} / \mathrm{dt}$ in relation to geomagnetic latitude (MLAT) and 2) The assessment on the number of maximum $\mathrm{dH} / \mathrm{dt}$ in relation to Local Time (LT).

The analysis was then extended to the investigation of relationship between SW parameter and the maximum value of $\mathrm{dH} / \mathrm{dt}$ in order to determine the most influential SW parameter affecting the occurrence of the GIC.

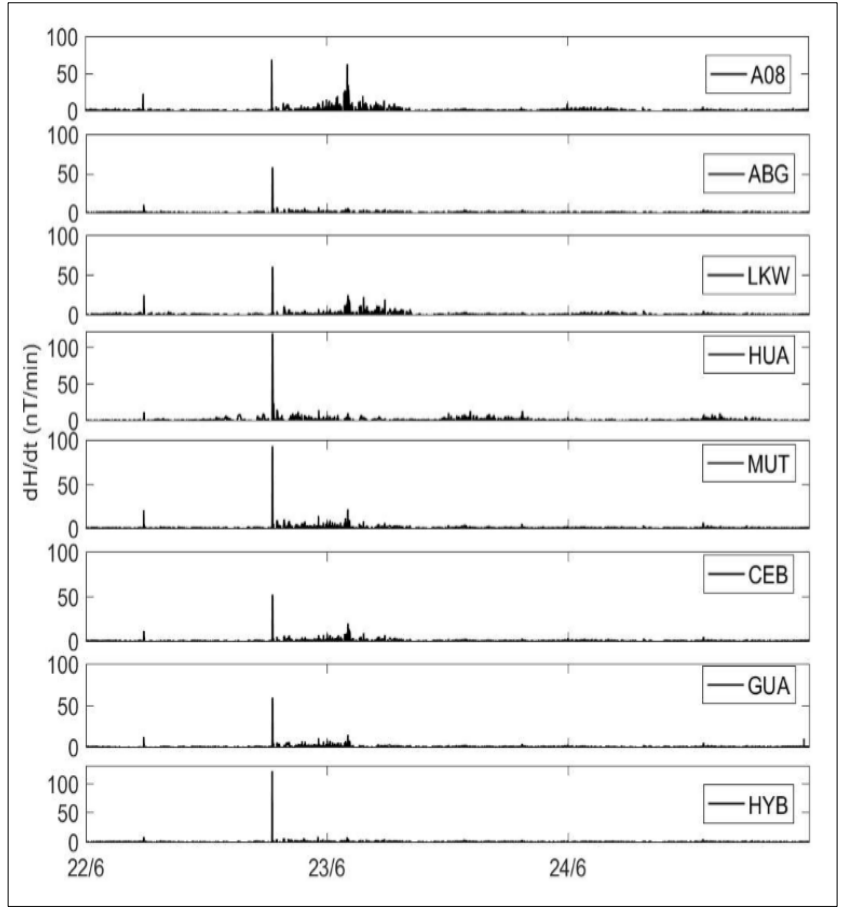

Fig. 3 An illustration of dH/dt analysis for Equatorial Region during the 22nd24th June 2015 Severe Geomagnetic Storm.

\section{A. Assessment on the averaged value of $d H / d t$ in relation to} Geomagnetic Latitude (MLAT)

The analysis of averaged value of GIC level is presented in Fig. 4. This figure reveals that the GIC's average value continues to increase as a result of enhancement by Equatorial Elecrojet (EEJ) when the equatorial station encountering the dip equator. From the figure also, it can be seen that for equatorial stations situated a few degrees away from the dip equator, the averaged value of GIC level is tending to decrease. The highest averaged $\mathrm{dH} / \mathrm{dt}$ value is observed at the latitude of $1.17^{\circ}$ with value of $76.47 \mathrm{nT}$ followed by latitude of $-0.85^{\circ}$ with value of $76.13 \mathrm{nT}$. Lowest $\mathrm{dB} / \mathrm{dt}$ value is observed at latitude of $14.11^{\circ}$ with the value of $33.35 \mathrm{nT}$.

\section{B. Assessment of number of GIC-related events in relation to} Local Time (LT)

The association between the No. of Maximum $\mathrm{dH} / \mathrm{dt}$ level on the basis of LT is presented in Fig. 5. The increasing pattern can be clearly perceived in the dayside starting from $0900 \mathrm{LT}$ to 1400 LT while the decreasing pattern can be observed starting from $1500 \mathrm{LT}$ to $2300 \mathrm{LT}$. There is no GIC occurrences observed at $0100 \mathrm{LT}, 0500 \mathrm{LT}, 0600 \mathrm{LT}, 1000 \mathrm{LT}, 1700 \mathrm{LT}$, $2000 \mathrm{LT}$ and $2200 \mathrm{LT}$. The most notable number of GIC-related events can be noticed at $1400 \mathrm{LT}$ with total of 11 events. This results propounds that GIC activity associated with the SC onset is likely to be occurred during the dayside, which also aligned with study performed by [17]. In the equatorial region, the pattern of $\mathrm{dH} / \mathrm{dt}$ is driven by the concentration of the currents circulated within this region where the current intensity rises from dawn to the highest value which is taken place at $1400 \mathrm{LT}$, and falls towards the dusk. These findings are in accordance with the results obtained by [18].

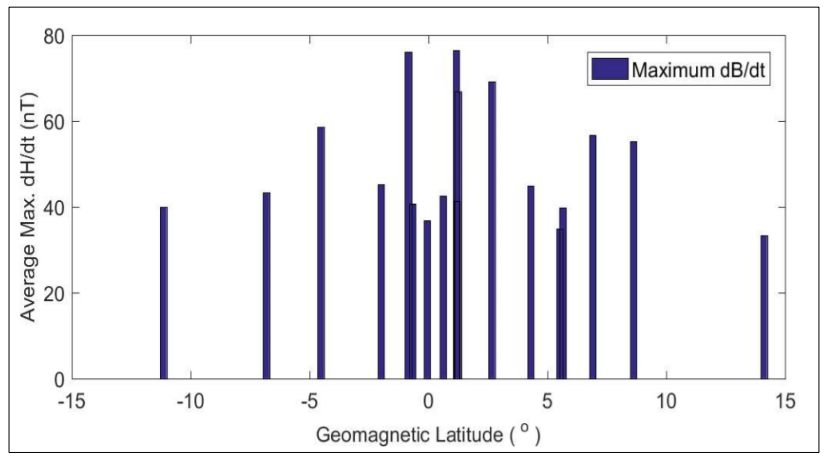

Fig. 4 The averaged value of maximum $\mathrm{dB} / \mathrm{dt}$ in equatorial region

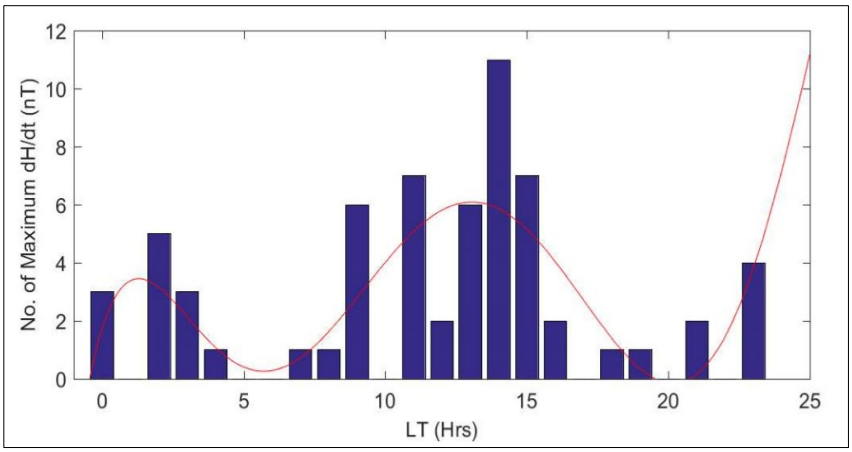

Fig. 5 The number of maximum $\mathrm{dH} / \mathrm{dt}$ depending on local time (LT) in equatorial region. The growing and decreasing trend of maximum $\mathrm{dH} / \mathrm{dtare}$ represented by the red solid line

\section{The Correlation Assessment between SW Parameter and $d H / d t$ level in equatorial region}

With the aim of identifying the relationship between the SW Parameter and $\mathrm{dH} / \mathrm{dt}$, the analysis is focused on the geomagnetic storm event occurred during 22nd June - 24th June 2015 as presented in Fig. 2. The hourly correlation analysis is performed specifically on that particular date to discover which SW parameter has greatest effect on the level of $\mathrm{dH} / \mathrm{dt}$ at equatorial region. The correlation analysis had been focused on several SW parameters which are $\varepsilon$ Parameter, Pdyn 
and IMF Bz Component. The involved equatorial stations have been divided into 3 continents which are American Sector, African Sector and Asian Sector. From this analysis, the correlations analysis between SW parameter and $\mathrm{dH} / \mathrm{dt}$ level during the severe geomagnetic storm at different sectors can be studied. The outcome of the correlation assessment between hourly Solar Wind Input Energy ( $\varepsilon$ Parameter) and hourly $\mathrm{dH} / \mathrm{dt}$ level for American, African and Asian sector are as presented in Fig. 6. From this analysis, it can be observed that, equatorial stations at three sectors have better correlation with $\varepsilon$ Parameter. The highest correlation is observed at the African sector with $r=0.7029$ followed by American Sector with $r=$ 0.6813 and Asian Sector with $r=0.6773$. This finding has implied that the energy dissipations from the $\mathrm{SW}$ are responsibled for affecting the GIC level in equatorial stations. The energy transmitted from the SW has been determined by $\varepsilon$ parameter and heavily depends on the intensity of southwardIMF Bz-Component. The heavy loading of energy has resulted in most of of GIC-related events in equatorial region during solar cycle 24 .

Further correlation analysis had been performed between hourly Solar Wind Dynamic Pressure (Pdyn) and hourly GIC level on 21st - 23rd June 2015 as depicted on Fig. 7. The analysis of the equatorial stations in American, African and Asian sector has revealed that high correlation is observed at equatorial station located at American Sector and African sector with correlation coefficient, $r=0.6844$ and $r=0.6538$ respectively. Slightly lower correlation is observed at A08 (Davao) station with correlation coeffiecient $r=0.3478$. This result suggested that Solar Wind Dynamic Pressure (Pdyn) plays an important role in triggering most of GIC occurrences in equatorial region, which is consistent with the studies done by B. Carter et al. [19]. The rise in Pdyn has led to an increase in magnetopause current's strength which is the driving force behind GIC occurrence in equatorial region.

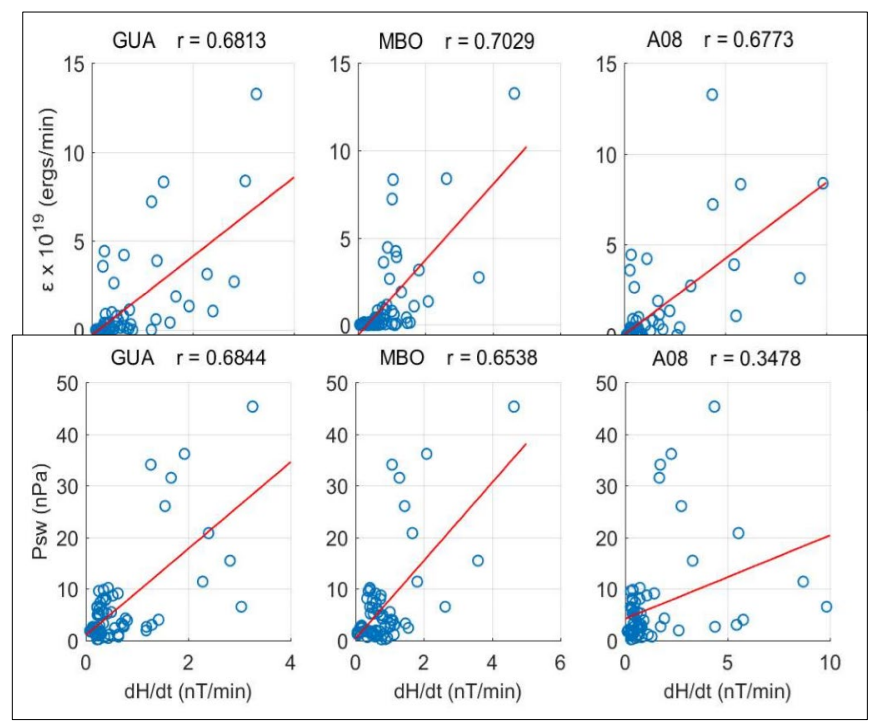

Fig.7 The Hourly Correlation between Pdyn Parameter and dH/dt level of Equatorial region in American (GUA), African (MBO) and Asian (A08) Sectors on 21 st - 23rd June 2015.
The analysis is extended to the correlation assessment between hourly IMF Bz component and hourly GIC level at equatorial stations on 21 st - 23rd June 2015 as shown in Fig. 8. The analysis of the equatorial stations at American, African and Asian sector shows that there is low negative correlation between IMF Bz component and GIC level where the lowest negative correlation belongs to GUA station at American Sector. The low negative correlation suggested that GIC activity has low dependence on southward-pointed IMF $\mathrm{Bz}$ component.

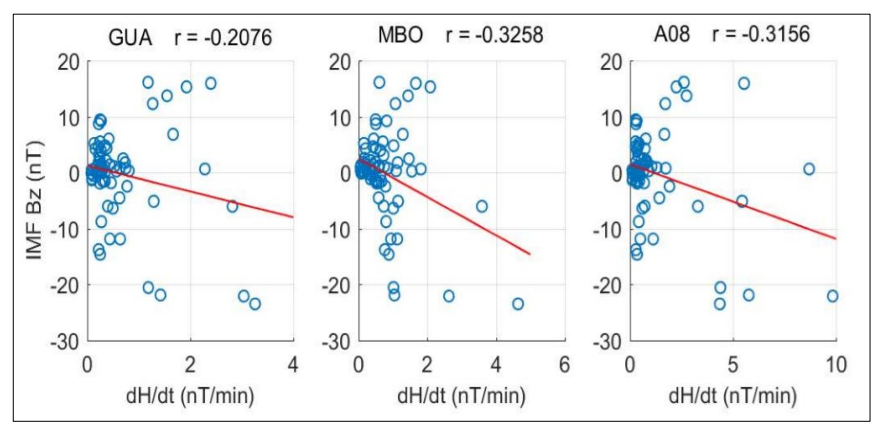

\section{CONCLUSIONS}

A detailed analysis has been carried out in this study in characterizing the occurrence of GIC in equatorial region over

Fig. 8 The Hourly Correlation between IMF Bz component and dH/dt level of Equatorial region in American (GUA), African (MBO) and Asian (A08) Sectors on 21st - 23rd June 2015.

solar cycle 24 in the course of 9 severe geomagnetic storms. The analysis covers the assessment of averaged Maximum $\mathrm{dH} / \mathrm{dt}$ value in relation to geomagnetic latitude (MLAT), assessment of number of maximum $\mathrm{dH} / \mathrm{dt}$ depending on Local Time (LT) and the correlation assssment between SW parameters and the GIC levels. The results revealed that as the geomagnetic latitude (MLAT) approaching dip equator $\left( \pm 3^{\circ}\right)$, an increasing pattern of averaged $\mathrm{dH} / \mathrm{dt}$ value could be seen due to the amplification of equatorial electrojet (EEJ). While the second analysis has depicted that most the GIC activities during solar cycle 24 occurred at the dayside concentrating on time range of $0900 \mathrm{LT}$ to $1400 \mathrm{LT}$ due to high current circulation during dayside. The results from the correlation analysis has revealed that the GIC activities at equatorial region during solar cycle 24 show high dependence in $\varepsilon$ Parameter and Pdyn parameter, while least dependence relationship is observed in IMF Bz component parameter. From the results also, it can be deduced that high occurrence of GICs activities at equatorial region happened during the interplanetary shock arrival and geomagnetic onset. It associates well with the high magnetopause current due to high SW dynamic pressure during the magnetospheric compression. Besides the SW parameter, the local parameter such as underground conductivity and skin depth also contributed to the GIC phenomenon. In order to go for detail characterization of GIC occurrence and understanding of physical mechanism of GICs, the research of combination of local parameters and SW parameters should be considered in the next study. 


\section{ACKNOWLEDGMENT}

All of costs associated with this project are funded by a grant under the grant programme of Fundamental Research Grant (600-IRMI/FRGS 5/3 (382/2019)) awarded by Ministry of Higher Education (MOHE). Great managements and support has been provided to allow the goals of the project to be further realized. The authors also would like to acknowledge OMNIWeb and SUPERMAG network for their contribution to data collection and interpretation in this study.

\section{REFERENCES}

[1] C. T. Gaunt, "Why Space Weather Is Relevant to Electrical Power Systems," Sp. Weather, 2016, doi: 10.1002/2015SW001306.

[2] D. J. Knipp, "Synthesis of Geomagnetically Induced Currents: Commentary and Research," Space Weather. 2015, doi: 10.1002/2015SW001317.

[3] A. Viljanen, "Relation of geomagnetically induced currents and local geomagnetic variations," IEEE Trans. Power Deliv., 1998, doi: 10.1109/61.714497.

[4] R. Pirjola, "Geomagnetically induced currents during magnetic storms," IEEE Trans. Plasma Sci., 2000, doi: 10.1109/27.902215.

[5] Z. M. K. Abda, N. F. Ab Aziz, Mohd Zainal Abidin Ab Kadir, and Z. A. Rhazali, "A review of geomagnetically induced current effects on electrical power system: Principles and theory," IEEE Access, 2020, doi: 10.1109/ACCESS.2020.3034347.

[6] V. N. Rajput, D. H. Boteler, N. Rana, M. Saiyed, S. Anjana, and M. Shah, "Insight into impact of geomagnetically induced currents on power systems: Overview, challenges and mitigation," Electric Power Systems Research. 2021, doi: 10.1016/j.epsr.2020.106927.

[7] A. Pulkkinen, S. Lindahl, A. Viljanen, and R. Pirjola, "Geomagnetic storm of 29-31 October 2003: Geomagnetically induced currents and their relation to problems in the Swedish high-voltage power transmission system," Sp. Weather, 2005, doi: 10.1029/2004SW000123.

[8] A. Pulkkinen, E. Bernabeu, J. Eichner, C. Beggan, and A. W. P. Thomson, "Generation of 100-year geomagnetically induced current scenarios," Sp. Weather, 2012, doi: 10.1029/2011SW000750.

[9] C. M. Ngwira, A. Pulkkinen, F. D. Wilder, and G. Crowley, "Extended study of extreme geoelectric field event scenarios for geomagnetically induced current applications," Sp. Weather, 2013, doi: 10.1002/swe.20021.

[10] J. J. Love, P. Coïsson, and A. Pulkkinen, "Global statistical maps of extreme-event magnetic observatory $1 \mathrm{~min}$ first differences in horizontal intensity," Geophys. Res. Lett., 2016, doi: 10.1002/2016GL068664.

[11] Z. I. A. Latiff, N. M. Anuar, M. H. Jusoh, and S. A. E. A. Rahim, "Latitudinal investigation on the variation of solar wind parameters towards geomagnetically induced currents during 7-8 September 2017 disturbed period," 2019, doi: 10.1109/ICSEngT.2018.8606364.

[12] F. A. M. Kasran, M. H. Jusoh, A. Yoshikawa, and Z. M. Radzi, "The Time Derivative of the Horizontal Geomagnetic Field for the Low Latitude MAGDAS Langkawi Station for the Estimation of Geomagnetically Induced Current," Sp. Sci. Commun. Sustain., pp. 57-71, 2018, doi: 10.1007/978-981-10-6574-3_6.

[13] E. Timuçin, S. Erat, and E. Yaşar, "THE USE OF HORIZONTAL GEOMAGNETIC FIELD COMPONENTS FOR ESTIMATION OF GEOMAGNETICALLY INDUCED CURRENT OVER TURKEY DURING SPACE WEATHER EVENTS," Turkish J. Eng., 2020, doi: $10.31127 /$ tuje. 572457 .

[14] D. M. Oliveira and C. M. Ngwira, "Geomagnetically Induced Currents: Principles," Brazilian Journal of Physics. 2017, doi: 10.1007/s13538-017-0523-y.

[15] E. O. Falayi and N. Beloff, "Estimating Geomagnetically Induced Currents," Can. J. Pure Appl. Sci., vol. 4, no. 2, pp. 1187-1197, 2010.

[16] W. D. Gonzalez et al., "What is a geomagnetic storm?," J. Geophys. Res., 1994, doi: 10.1029/93ja02867.

[17] Z. I. A. Latiff, M. H. Jusoh, and K. Burhanudin, "Assessment of Geomagnetically Induced Currents in Low Latitude Regions with respect to Severe Geomagnetic Storm over Solar Cycle 24," J. Phys. Conf. Ser., vol. 1768, no. 1, 2021, doi: 10.1088/1742$6596 / 1768 / 1 / 012002$

[18] S. N. Ibrahim et al., "First geomagnetic observation at sabah, malaysia by using MAGDAS array," Int. J. Simul. Syst. Sci. Technol., vol. 17, no. 41, pp. 30.1-30.8, 2017, doi: 10.5013/IJSSST.a.17.41.30.

[19] B. A. Carter et al., "Geomagnetically induced currents around the world during the 17 March 2015 storm," J. Geophys. Res. Sp. Phys., 2016, doi: 10.1002/2016JA023344.

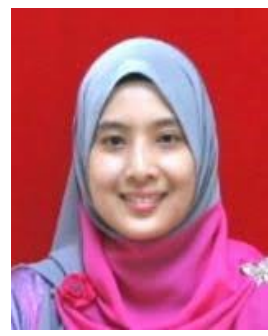

Zatul Iffah Abd Latiff is a senior lecturer in College of Engineering, UiTM Cawangan Johor, Kampus Pasir Gudang. She received a Bachelor of Engineering degree in Electrical Engineering from Korea University, South Korea in 2009 and her Master of Science in Telecommunication and Information Engineering from Universiti Teknologi MARA (UiTM), Malaysia in 2013. She currently pursuing her study for Ph.D. in Space \& Earth Electromagnetims in UiTM Shah Alam. She is one of the co-researchers of MAGDAS (Magnetic Data Acquisition System) network who is responsible for monitoring and maintaining one of the MAGDAS observatories located in Johor, Malaysia.

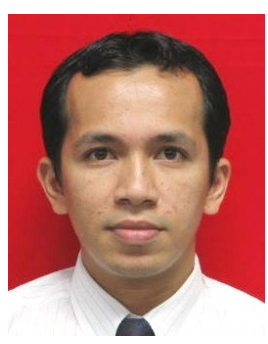

Mohamad Huzaimy Jusoh is a Senior Lecturer in College of Engineering, UiTM Shah Alam. He received a bachelor's degree in Electronic Engineering in 2004 from UiTM Shah Alam. He received his Doctor of Engineering from Kyushu University, Japan in 2013. Previously he works as an engineer at Sony EMCS Malaysia. He is currently working as a senior director also as Director for Satellite Communication at the Faculty of Electrical Engineering, Universiti Teknologi MARA (UiTM), Malaysia. His current research is on Space and Earth Electromagnetism, Polar exploration, Magnetic Data Acquisition System (MAGDAS), Occupational Safety and Health, and Satellite Communication. 